ISSN: 2162-3104 Print/ ISSN: 2166-3750 Online

Volume 8, Issue 2 (2018), pp. 1256-1263

(C) Journal of International Students

http://jistudents.org/

doi: $10.5281 /$ zenodo. 1250425

\title{
Building a Community of Learners In and Outside the Classroom
}

\author{
Erin Knoche Laverick \\ The University of Findlay, USA
}

\begin{abstract}
Learning Communities (LCs) and First-Year Seminars (FYS) are common support systems for college students. This article explores the use of such systems with undergraduate international students in their first semester of study as a means to help them better acclimate to campus life and rigorous classroom expectations.
\end{abstract}

Keywords: first-year seminars, international students, learning communities

Most college freshmen experience some sort of roadblock in their first semesters of study. Whether it be homesickness or problems with their roommates, these roadblocks can hinder their academic performances. Such conflicts are often heightened for international students who can suffer from culture shock and/or poor academic English-language skills such as the inability to write research papers, take notes during a lecture, use library resources properly, or participate in class discussions. To help international students adjust to a new culture and academic environment, it is important that they have a support system in place when they arrive at a university.

\section{LITERATURE REVIEW}

One common type of support system used in higher education is Learning Communities (LCs). A LC is a group of students who have common academic goals, shared interests, or common backgrounds. Once placed in a 
LC, students often take common courses to help establish rapport and academic support amongst the group. Current research has shown that when students are required to take similar courses and discuss their projects, homework, etc. both in and outside the classroom, they have a richer and more meaningful college experience. According to Rocconi (2011) LCs have two distinct features: 1) collaborative and 2) connected learning. "Shared or collaborative learning comes from students enrolling in several common courses, thereby increasing the likelihood of an integrated social and academic experience. Connected learning comes from learning communities being organized around a central theme or topic, such as college major or interest" (p. 179). It is through collaborating both in and outside the classroom and connecting with their peers, staff, and instructors about topics of interest that students find greater success.

Previous research has demonstrated that LCs promote student growth (Browne \& Minnick, 2005), improve interaction with faculty (Garrett \& Zabriskie, 2004), increase retention (Lei et al., 2011 \& Goldman, 2013), and improve academic performance (Tampke \& Durodoye, 2013). Most of the current research on LCs focuses on populations of domestic students, including transfer students, online learners, and traditional freshmen. Research on LCs and international students is limited. However, some universities offer mentor programs in which faculty and staff assist students in acclimating to campus life. In their research, Hellsten and Prescott (2004) found that international students valued having mentors and viewed them as parental figures. Yet, due to the mentors' busy schedules, they were not available to meet as often as the international students would have preferred. LCs with an embedded mentor could be a remedy, as the students would not only have a mentor but also a group of peers to depend on for support and guidance.

Another common type of support system for college students is First-Year Seminars (FYS). Some universities have created FYS specifically for international students. For example, Yan and Sendall (2015) examined the impact of FYS on international students. They found the courses address the different challenges international students face in their first year of study and better prepare them socially and emotionally for college. Encouraging collaboration and offering students a "safe space" to learn, ask questions, and become connected to the university, whether it be through LCs or FYS, is indeed important for any student population, but especially international students. 


\section{CREATING A COMMUNITY OF LEARNERS}

The University of Findlay, a small private university in Northwest Ohio, hosts over 500 international students on F-1 visas each year. UF international undergraduate students begin their academic programs of study following two distinct paths. Students, who are not proficient in the English language, must complete the Intensive English Program (IEP) on campus before they begin their undergraduate studies. Students who submit an iBT TOEFL score of 61 or higher or an IELTS score of at least 6.0 to prove English language proficiency begin their undergraduate courses directly. Both groups of students are required to take an academic writing course for English Language Learners (ELLs) in their first semester of undergraduate study. This course is housed in the IEP and as part of regular programmatic assessment, course completion rates and percentages of student plagiarism are tracked by the IEP director.

Historically, both the direct admit students and those who studied in the IEP have struggled to find academic success in the writing course. For example, the program's target assessment goal is for $100 \%$ of students to successfully complete the composition course in their first semester of study. The chart below shows the completion rates for the course before the IELP implemented intervention.

Table 1. Program assessment data

\begin{tabular}{ll}
\hline Semester & Completion Rate \\
\hline Fall 2014 & $76 \%$ \\
Spring 2015 & $67 \%$ \\
Fall 2015 & $81 \%$ \\
\hline
\end{tabular}

Because students were struggling in this course, focus groups were conducted with students who took the composition class in order to better understand their needs. Through the focus groups, it became evident that students were not only struggling in the writing course. Students expressed that they were overwhelmed by the rigor of an undergraduate program and did not know how to navigate campus, approach professors for assistance, or ask for help when they felt alienated or lost. In other words, they lacked a support system and required a better sense of community to assist them through their first semester of study. The IEP decided intervention was 
necessary and created the Foundations Program to better assist the undergraduate international students in their first semester of study.

The first goal of the Foundations Program was to create a better sense of community both in and outside the classroom for the students. As previously noted, Rocconi (2011) wrote that one important feature of LCs is that students enroll in similar classes so they can collaborate and feel connected both inside and outside the classroom. In the Foundations Program, students register for six common credit hours in their first semester of study. Below is a list of the courses students register for in their first semester.

Table 2: Foundations Program course requirements

\begin{tabular}{lll}
\hline Course Title Course Description &
\end{tabular}

Writing Review I for

This writing course is designed to prepare non-

Non-native Speakers

(4 credits) native speakers of English for composing academic tasks. The course will stress the use of the writing process by having students compose a formal informative research paper. Emphasis is placed on MLA documentation. Assignments will develop students' analytical and critical thinking skills.

College Reading ( 1 credit)

This course is designed to help students develop vocabulary and comprehension skills appropriate for university- and professional-level reading.

First Year Seminar (1 This class will help prepare students for their credit) undergraduate studies by acquainting them with study skills and time management. It will also introduce students to campus life and culture.

The above courses were selected because they focus on building students' language skills and cultural knowledge. As previously noted, the writing course is required in the first semester of study. However, in the past, students could take "College Reading" whenever they chose. By requiring this course in the first semester, students practice their academic reading skills in tandem with their writing skills. Requiring these skill-based courses also allows students to hone their English-language skills while taking content courses. Research shows that it takes 5-7 years for ELLs to acquire academic English-language skills (Cummings, 1985). Therefore, it 
is unrealistic to expect our international students to be completely proficient in the English-language when they enter their undergraduate programs of study. This balance of skill and content knowledge ensures that students are not overwhelmed and can work with each other outside of class.

Also, a FYS was designed to help students acclimate to The University of Findlay both academically and culturally. In the course, students develop short and long-term academic goals, identify and use appropriate educational resources, use strategies for working effectively within a group setting, and develop the skill of self-reflection. What makes this FYS unique is that once students enroll in the FYS, they are divided into small groups and placed into LCs. Each LC is assigned a faculty/staff mentor. The mentor shepherds the students through their first semester, assisting them with their cultural and linguistic needs, accompanying them to on-campus events, and being a person they can turn to if they are homesick and overwhelmed.

\section{DISCUSSION}

In piloting the Foundations Program, the FYS found great success. A survey was proctored at the end of the semester to ascertain the value of the Foundations Program. All sixteen students particularly found value in the FYS course for two main reasons: 1) they made new friends, and 2) they improved their English-language skills, specifically their writing skills. Fourteen out of the sixteen students strongly agreed that the course helped them acclimate to UF and make friends. One student noted, "It was nice to meet and work with other international students because we are all in the same situation." In addition, another student wrote, "I like this class because this class helped me to interact with friends and develop my skill of writing." The FYS offered students a safe environment in which they could interact with each other and build a support system. They made friends and were able to socialize outside the classroom.

In addition, all sixteen students agreed that their English-language skills improved by taking the FYS, with six students specifically noting an improvement in their writing skills. One student wrote in the survey, "This class made me improve my English skills and it was really helpful. It would have been really hard to take my undergraduate classes without having the support of the class." And another noted, "I liked each and everything about this program. I improved my English skills, I got to make more friends 
because of group projects. And all of the above, my teacher was the best part because she always helped us in every way she can." The survey results and students' comments are in line with Yan and Sendall's (2015) findings, which showed that FYSs help international students become more knowledgeable about college resources, prepare for the American classroom environment, make friends, and improve language skills.

While students valued the FYS, they did not make use of their LCs and did not meet regularly with their mentors. Three out of five mentors completed and returned their surveys. All three mentors noted that they struggled to find common meeting times and that many of the students did not show up for planned activities. In addition, one of the mentors recommended, "At opening $\mathrm{mtg}$ [sic] it might be good to schedule all gatherings so that they are on the calendar." In reflecting on the mentors' feedback, it became apparent that the instructor of the FYS needed to further embed the mentoring into the course.

\section{CONCLUSION}

After reflecting on the first semester and analyzing the data, revisions to the Foundation Program were made for the subsequent semesters. Students continue to enroll in the writing, reading, and FYS courses along with two or three content courses of their liking. To encourage students to make better use of their mentors, the LCs have been better embedded into the FYS class. As one of the course objectives is for students to practice the skill of selfreflection, students now must journal about the meetings with their mentors. The FYS instructor also decided to introduce the students to their mentors earlier in the semester. For example, mentors are now invited to a luncheon before the start of each semester. At the luncheon mentors receive training about how to best assist the students. Once students settle into the semester (typically the 2nd or 3rd week), they are divided into the LCs. The FYS instructor organizes and hosts a meet-and-greet with the students and their mentors. The informal event serves as an icebreaker for the students and mentors to learn more about each other, schedule their meetings, and plan activities.

In addition, poor academic performance is now tracked through a retention system called Starfish. All instructors campus-wide can flag students who are struggling in their courses. Students, who struggle academically, are now also required to meet with an academic coach to 
discuss their struggles and/or progress. This additional support system allows the mentors to solely focus on engaging the students by attending cultural events and activities on campus and within the community, helping them adjust to their new lives at the university.

Program assessment demonstrates the overall effectiveness of the Foundations Program. Since implementing the program, more students are completing the required composition course. In spring 2017, $95 \%$ of the students completed the class, close to the program's goal of $100 \%$ completion. Thanks to intervention, students are finding better success in their coursework, meeting people, and learning about on-campus resources to assist them in their undergraduate studies. With a strong a foundation, the students will find better success in and outside the classroom.

\section{REFERENCES}

Browne, M.N., \& Minnick, K.J. (2005). The unnecessary tension between learning communities and intellectual growth. College Student Journal, 39(4), 775783.

Cummings, J. (1985). Empowering Minority Students. California Association for Bilingual Education.

Garrett, M.D., \& Zabriskie, M.S. (2004). The Influence of living-learning program participation on student-faculty interaction. Journal of College \& University Student Housing, 33(1), 38-44.

Goldman, C. (2013). A cohort-based learning community enhances academic success and satisfaction with university experience for first-year students. Canadian Journal for the Scholarship of Teaching and Learning, 3(2), 119.

Hellsten, M., \& Prescott, A. (2004). Learning at university: The international student experience. International Education Journal, 5(3), 344-351.

Lei, S. et al. (2011). Academic cohorts: benefits and drawback of being a member of a community of learners. Education, 3, 497-504.

Rocconi, L. (2011). The Impact of Learning Communities on First Year Students' Growth and Development in College. Res High Educ, 52, 178-193 DOI: $10.1007 / \mathrm{s} 11162-010-9190-3$

Tampke, D. R., \& Durodoye, R. (2013). Improving academic success for undecided students: A first-year seminar/learning community approach. Learning Communities Research and Practice, 1(2), Retrieved from $\mathrm{http}: / /$ washingtoncenter.evergreen.edu/lcrpjournal/voll/iss $2 / 3$

Yan, Z., \& Sendall, P. (2015). First year experience: How we can better assist firstyear international students in higher education. Journal of International Students, 6(1), 35-51. 
ERIN KNOCHE LAVERICK, PhD, is an Associate Professor and Chair of the Department of Language and Culture at The University of Findlay. Her major research interests lie in the area of academic literacies and academic support for international students. Email: knoche@findlay.edu

Manuscript submitted: October, 2016

Manuscript revised: August 19, 2017 Accepted for publication: September 18, 2017 